\title{
Miscanthus stem fragment - reinforced polypropylene composites: development of an optimized preparation procedure at small scale and its validation for differentiating genotypes \\ Jordi Girones ${ }^{\mathrm{a}}$, Loan Vo ${ }^{\mathrm{a}}$, Stéphanie Arnoult ${ }^{\mathrm{b}}$, Maryse Brancourt-Hulmel ${ }^{\mathrm{c}}$, Patrick Navard ${ }^{\text {a,** }}$
}

a-Mines ParisTech, PLS - Research University, CEMEF - Centre de Mise en Forme des Matériaux, UMR CNRS 7635, CS 10207, Rue Claude Daunesse, 06904, Sophia Antipolis Cedex (France) jordi.girones@mines-paristech.fr; thi-to-loan.vo@mines-paristech.fr; patrick.navard@mines-paristech.fr b-INRA, UE GCIE, Estrées-Mons, F-80203 Péronne, France

Stephanie.Arnoult@mons.inra.fr c-INRA Agrolmpact, Site d'Estrées-Mons BP 50136, 80203 Péronne cedex France maryse.brancourt@mons.inra.fr

Correspondence should be addressed to:

Patrick Navard

Mines ParisTech

Centre de Mise en Forme des Matériaux (CEMEF)

UMR CNRS 7635, CS 10207

06904 - Sophia Antipolis CEDEX (France)

E-mail: patrick.navard@mines-paristech.fr

\section{$\underline{\text { Abstract }}$}

The production of ligno-cellulosic biomass-based composites requires the development of new methodologies to evaluate the reinforcement potential of a given biomass such as miscanthus, studied in the work. Miscanthus stems coming from thirteen genotypes were broken into elongated fragments and mixed with polypropylene composites in an internal mixer. The aim is to find the best protocol able to discriminate miscanthus genotypes for their reinforcement capabilities. The following process parameters were optimized in order to maximize the reinforcement effect of the stem fragment filler: mixing parameters (mixing time, rotor speed and chamber temperature), temperature, fragment content, size and length distributions and coupling agent. The relationship between the process parameters and the mechanical properties of composites were analyzed to evaluate the influence of genotype on reinforcement performances, showing the robustness of the protocol in effectively discriminating genotypes according to their reinforcing capacity.

\section{Keywords}

Particle-reinforced composite; Biocomposite; Natural Fibers; Mechanical properties

\section{Introduction}

The most common fillers used to improve the properties of commodity polymers are glass fibers, which offer the advantages to be cheap and to have very good mechanical properties. However, they suffer several disadvantages such as density, bad environmental footprint, difficulties to be recycled (loss of mechanical properties due to successive fiber length reductions during reprocessing [1-3]) and a high abrasion effect 
on injection mold surfaces. For several decades, the possible substitution of glass fibers by more eco-friendly materials derived from lignocellulosic biomass has been subjected to an extensive attention from the scientific community. Such fillers have clear advantages, such as a density lower than glass fibers, a non-abrasive character, a low environmental impact and the possibility to be recycled [4-7]. They have a very good acceptance by the market, leading to several applications, mainly in the automotive sector [8,9] and as wood replacement in cladding and decking [10,11]. However, natural renewable fillers have intrinsic properties lower than their glass fiber counterpart, a low thermal resistance which restricts the type of polymer matrices they can be used with and a high hydrophilicity which is posing problems when used with most thermoplastics such as polyolefins [12-14]. In deep contrast with glass fibers which have always the same composition and diameter, biomass pieces have chemical and physical characteristics which are very variable. Biomass composition and structure varies with the types of tissue present in the biomass part $[15,16]$, the cultivation conditions (climate, soil quality) $[17,18]$, the harvesting method and period of time [19,20], and, if applicable, the extraction methods [21-23]. However, these parameters are not often taken in consideration and in particular the genotype of the biomass which is used. Many articles and reviews report the preparation of polymer composites and their mechanical properties with multiple combinations of biomass sources and matrix polymers [24-26]. More rarely, the influence of processing parameters and biomass preparation were studied [27-29]. In general, it is accepted that the mechanical properties of composites are directly correlated with the strength of the reinforcement filler (rule of mixtures). For this reason, the intrinsic mechanical properties of many reinforcing fibers have been evaluated, and correlations with their size, diameter or position in the plant have been detected [30-33]. Most of these parameters are obviously genotype-dependent, an aspect which has never extensively been studied at the plant species level. To investigate the effect of genotypes, and thus build a correlation between genotype-dependent reinforcement properties and composite strength, all other parameters than genotype must remain unchanged.

Among bioenergy crops, the rhizomatous perennial miscanthus represents a good candidate, as the main cultivated species (Miscanthus x giganteus) is highly productive in temperate climates, with low nutrient requirements due to its ability to translocate nutrients from aboveground organs to the rhizomes in autumn [34]. The nutrients that are stored in the rhizomes are then available for the next year of growth through remobilization during spring regrowth, which reduces the dependence on fertilizers [35]. The choice of this Poaceae grass therefore combines high potential for yearly biomass production with a minimal impact on the environment [36].

The general objective of our work is to discriminate miscanthus genotypes and to identify their components and structures which maximize composite properties in order to adapt this species to industrial applications. To attain this goal, the development and validation of a robust procedure able to discriminate miscanthus genotypes is needed and is the subject of this article. We hypothesized that the developments of such procedure for stem fragment-reinforced polypropylene composites would be feasible at small scale and would enable the discrimination of miscanthus genotypes. The filler is composed of miscanthus pieces obtained by grinding the stems, sieving and then used without any treatment.

The objective is to discriminate miscanthus genotypes. The amount of leaves attached to the stem during harvest depends on harvesting conditions. As it will be shown, these 
leaves are producing very small dust-like particles which are strongly decreasing the mechanical properties of composites and are preventing a proper comparison between genotypes. After grinding, the stem fragments were sieved in order to select a given fraction for comparing genotypes and suppress dust. The size of stem fragments is decreasing during processing and this decrease is genotype-dependent. It is thus a characteristic of the genotype. The evaluation of the mechanical properties of composites must thus be performed using a similar stem fragment size for all genotypes if willing to compare genotypes..

In forthcoming works, this procedure will be used to study the detailed influence of biochemical compositions and histological structures on the mechanical properties of miscanthus stem fragment-filled polypropylene composites, in order to create new varieties with a composition tailored for composite uses.

\section{Materials and Methods}

\subsection{Materials}

Two homopolymer polypropylenes were used as polymeric matrices: PPH5060 (produced by Atofina and specially compounded by Addiplast to minimize the amount of additives , $\mathrm{MVI}=6 \mathrm{~g} / 10 \mathrm{~min}$ at $230^{\circ} \mathrm{C}, 2.16 \mathrm{~kg}$, tensile strength at yield $31.2 \pm$ $1.6 \mathrm{MPa}$ ) and Addilene (by Arkema, MVI $=70 \mathrm{~g} / 10 \mathrm{~min}$ at $230^{\circ} \mathrm{C}, 2.16 \mathrm{~kg}$, tensile strength at yield $24.0 \pm 0.6 \mathrm{MPa}$ ). Maleic anhydride-grafted polypropylene (MA-g-PP) was used as a coupling agent (or compatibilizer), provided by Eastman (G-3015). Thirteen clones of miscanthus were tested in the Picardie region of Northern France $\left(49^{\circ} 53 \mathrm{~N}, 3^{\circ} 00 \mathrm{E}\right)$ at the INRA experimental unit in Estrées-Mons according to a three randomised complete block design. Two clones were identified as M. $x$ giganteus clones: the variety Floridulus (FLO) and a clone from the Agriculture Development and Advisory Service in Great Britain (GIGB). Nine clones were identified as $M$. sinensis clones: Ferner Osten (FER), Flamingo (FLA), Goliath (GOL), Graziella (GRZ), Malepartus (MAL), Purpurascens (PUR), Rotsilber (ROT), Silberfeder (SIL) and Yaku Jima (YAK). Finally, two clones were identified as M. sacchariflorus clones: one hybrid (H5) from the Danish Aarhus University and one clone from Chombard nursery (SAC). The trial was planted by hand in spring 2007 at a rhizome planting density of two plants per $\mathrm{m}^{2}$. No irrigation was applied excepting during the first year of cultivation. No fertilizers and phytochemicals were applied during the entire plantation time and, in order to preserve the quality of the crop for industrial testing and genotype comparisons, the weeds were controlled each year by hand and machine hoeing. The plants were harvested each year at the end of winter at over-maturity.

For the composite preparations of this work, stems were harvested in February 2013 and provided in $80 \mathrm{~cm}$ long sections including the eventual remaining leaves. Prior to compounding, the stem fragments were dried in an air circulating oven (FED line Binder) at $70^{\circ} \mathrm{C}$ for at least five hours. Prior to use, MA-g-PP coupling agent was conditioned at $70^{\circ} \mathrm{C}$. MA-g-PP was added to the compounding system once the reinforcing fragments and PP matrix mixing was achieved.

\subsection{Milling/sieving of miscanthus plants}

After being manually cut to approximately $5 \mathrm{~cm}$ with a scissors, stem pieces were ground down to mm size with a polymer pelletizer (Hellweg M50). This slow running apparatus (280rpm) generated very low amounts of dust, whilst its $2.5 \mathrm{~mm}$ sieve allowed some control of stem fragment size. This first grinding process produces stem fragments consisting of elongated particles with a very broad size distribution. Measured by 
optical microscopy, the average length of these fragments was around 5mm, although some fragments could be up to $2 \mathrm{~cm}$ long. An average aspect ratio (length over diameter) of about 6 was measured. In order to further reduce the average length and limit size dispersion, a second milling process was conducted using a coffee mill (Carrefour home), followed by sieving in a Retsch AS200 Digit shaker (Retsch, Germany). Twenty grams of miscanthus were sieved with the shaker operating at $40 \mathrm{~mm}$ amplitude $(2 \mathrm{~mm} / \mathrm{g})$ for 5 minutes. Sieves with open pore sizes of 1000, 600, 400, 300, 200 and 100 $\mu \mathrm{m}$ were used. The dimensions of the fragments were measured by optical microscopy (Leica DM4500P) equipped with a high resolution 3-CDD numerical camera (JVC KY-F75U, $1360 \times 1024$ pixels. High resolution maps were obtained with the cartograph ${ }^{\circledR}$ Software. The lengths and widths of 100 to 300 individual stem fragments were measured using Ellix ${ }^{\circledR}$ software. Stem fragments with length below $100 \mu \mathrm{m}$ (or width below $20 \mu \mathrm{m}$ ) were removed from the study.

\subsection{Composite preparation}

Composite blends comprising 20 to $50 \%$ (w/w) miscanthus stem fragments were prepared using a Haake-rheomix intensive kinetic mixer. When used, MA-g-PP was added to the composite formulation at $5 \% \mathrm{w} / \mathrm{w}$ on dry fragment basis. For composites presenting a 30\% miscanthus content (such as in the genotype comparison) this corresponds to $1.5 \%$ on total composite weight. Composite blends were then granulated in a blade mill fitted with a $5 \mathrm{~mm}$ mesh and kept in an oven at $80^{\circ} \mathrm{C}$ to prevent moisture absorption. Test specimens were injection-molded in a Haake Minijet-II (Thermo Scientific) using a steel mold complying with the ISO-527-2-1BA specifications. 2.4. Mechanical characterization

Composite specimens were kept in a room conditioned at $23^{\circ} \mathrm{C}$ and $50 \% \mathrm{RH}$ for at least one week. At least six specimens for each preparation were tested with a Zwick Z2.5 testing machine (Zwick-Roell) operating at $0.02 \mathrm{~mm} / \mathrm{s}$. Young's modulus was calculated from the secant of the stress-strain curve at $0.05-0.25 \%$ deformation.

\section{Results and discussion}

\subsection{Process optimization}

In a preliminary study, composites were prepared with a general purpose injection grade matrix (PPH5060) and only one genotype (Miscanthus $x$ Giganteus) in order to maximize any effect due to viscous heating and detect potential thermal degradation problems. Compounding temperatures, mixing times and rotor speeds were tested in order to optimize the processing conditions. It was noticed that when the temperature of the internal mixer was set at over $180^{\circ} \mathrm{C}$, the temperature in the mixing chamber could attain values well over $200^{\circ} \mathrm{C}$, leading to naked-eye visible thermal degradation of miscanthus stem fragments. It was also found that to avoid clogging, miscanthus fragments had to be added in two steps in the melted polymer. Coupling agents had to be added after 5 min of mixing in order to limit its contact with any residual moisture and to reduce fiber attrition during mixing. After testing several combinations, it was established that a mild rotor speed of 60rpm and a mixing time of 9 minutes ensured a complete and repeatable dispersion of the stem fragments inside the polymer matrix. In order to maximize the influence of the reinforcement, its amount should be as high as possible. However, a slight drop in tensile strength of composites was observed when fragment content exceeded $40 \%$, due to possible uneven distribution of fillers, formation of aggregates or thermal degradation caused by the necessity to apply harsher injection-molding conditions due to the high viscosity of these materials. For these 
reasons, the processing parameters were optimized for composites with $30 \% \mathrm{w} / \mathrm{w}$ miscanthus content.

\subsection{Selection of stem fragment}

The milling process produced samples with a very wide fragment size distribution. However, given the well-known importance of the reinforcement aspect ratio, it was necessary to narrow the fragment length distribution by sieving. Figure 1 presents the length distributions of the fragments collected in the different sieves, from those that went through the $100 \mu \mathrm{m}$ sieve to those collected in the sieve with mesh size of $400 \mu \mathrm{m}$. Figure 1 shows that the sieving process allowed narrowing the fragment length distribution. Even though long fibers were able to go through the sieves (separation is based mainly upon diameter, not length), fragment distribution became progressively narrower as sieving progressed. A major result is that the sieving gave fractions free of dust particles, since all the tiny fractions went to the bottom sieve. In spite of the different length / diameter of the fragments, the aspect ratio of miscanthus fragments remained fairly constant at around 6-7 whatever the mean size was. After sieving, PP (PPH5060)-miscanthus composites comprising 30\% of miscanthus fragments were prepared with each of the different collected fractions. The results of tensile tests are given in figure 2. In the absence of coupling agents, none of the fragments used could effectively reinforce the PP matrix due to the bad quality of the filler-polymer interface and the low aspect ratio of the fragments. No statistically significant difference was observed between the composites prepared with the different fragment sizes. By the opposite, in materials containing MA-g-PP, miscanthus fractions showed a considerable reinforcing capacity, with enhancements in ultimate tensile strength in the order of 30$40 \%$ compared with the PP matrix. In addition, the effect of stem fragment size is clear, the ultimate tensile strength increasing with decreasing fragment size, hence with increasing specific surface area. It is commonly accepted that, as soon as the aspect ratio of the reinforcement is kept constant, the effectiveness of the reinforcement increases inversely to its size. The Young's modulus and elongation at break were not significantly affected by fragment length, suggesting that the increase in tensile strength was not caused by the changes in the quality of fragment dispersion but by an enhanced stress-transfer between the matrix and the filler.

\subsection{Effect of miscanthus genotype}

After having selected the processing conditions maximizing the mechanical properties of the composites, the protocol was modified in order to maximize the influence of the miscanthus filler, in order to have a chance to discriminate genotypes. With this goal in mind, we changed the PP matrix for another one having lower intrinsic mechanical properties (Addilene) and minimal amount of additives able to interact with the reinforcement. Following the previous results, the applied protocol was as follows. 50 grams of overnight dried stems (fractions of about $80 \mathrm{~cm}-1 \mathrm{~m}$, not cleaned of leaves / sheath) were milled and sieved. The fraction collected in the sieve of $100 \mu \mathrm{m}$ was used as reinforcement, whereas fractions collected in sieves with pore size higher than $100 \mu \mathrm{m}$ were grinded until they had the selected size. Composites comprising $30 \% \mathrm{w} / \mathrm{w}$ fragments were prepared in the internal mixing with the chamber temperature set at $180^{\circ} \mathrm{C}$ and rotor speed limited to $60 \mathrm{rpm}$. The coupling agent was added once all the components had been dispersed in the matrix. This protocol was used to test composites based on the thirteen different miscanthus genotypes. The variation of Young's modulus versus tensile strength is given in figure 3 and table 1, clearly showing that the devised 
protocol was able to discriminate genotype effect onto the final mechanical properties of the composites.

Depending upon the genotype, the tensile strength of the reinforced composites varied from 32 to $39 \mathrm{MPa}$ and the Young's modulus from 2.7 to 3.3GPa. Contrary to changes in strength and modulus, the elongation at maximum strength did not show any significant differences with genotype and in all cases remained around $2.4 \pm 0.1 \%$. The small aspect ratio of the reinforcing filler $(\mathrm{L} / \mathrm{d}=6)$ and the high melt volume index of the selected polymeric matrix account for such small capacity to sustain deformation. This lack of elasticity of the matrix may also account for the strong correlation between tensile strength and Young's modulus. Since most samples could sustain the same deformation (2.2-2.5\%), the strength of composites was directly proportional to their stiffness.

\subsection{Validation studies}

\subsubsection{Importance of the sieving process}

Depending on their biochemical composition and histological structure, genotypes were more or less easily grinded. The energy needed for grinding was not measured but is was seen that the most difficult genotypes to grind were the ones giving the best mechanical results when used for the preparation of composites. As already said above and proved below, the fact that leaves were producing dust which was decreasing mechanical properties imposed to sieve and select a common mean size of fragment for all genotypes in order to perform a meaningful comparison between them. In an industrial milling process, the individual separation of leaves is not feasible and the amount of leaves attached to the stem depends largely on the harvesting conditions and the characteristics of each genotype. In consequence, when milled in large quantities in industrial facilities, some genotypes generated mostly long rigid fragments while others, submitted to the same milling process, generated high amounts of irregular "dust" particles. Figure 4 represents the tensile strength of composites (Addilene matrix) reinforced with fragments obtained from six different miscanthus genotypes that were submitted to the same industrial milling and were not submitted to sieving prior to compounding. The tensile strength of the composites prepared varied from 29 and $33 \mathrm{MPa}$ depending on the genotype tested. Grinded and sieved in laboratory conditions, the same genotypes provided composites with tensile strength between 32 and 38MPa. Since all the other processing parameters were kept constant, the reasons for the differences in mechanical strength were assigned to the milling/sieving process. Even though the industrial milling was set to obtain fragments with an average fragment length of $500 \mu \mathrm{m}$ (as in the laboratory samples), the end product were samples with considerable amounts of dust particles $(20-30 \% \mathrm{w} / \mathrm{w})$. Interestingly, when sieving was conducted on the fragments, clear correlations could be found between the mechanical properties of composites, the amount of fragments collected in the sieve of $100 \mu \mathrm{m}$ $\left(\mathrm{R}^{2}=0.56\right)$ and particularly with the amount of dust particles in the samples $\left(\mathrm{R}^{2}=0.72\right)$. This result shows the necessity of removing these "dust particles" to obtain an efficient reinforcement. Without such removal, the mechanical properties of composites depended upon the amount of "dust" in the filler, which in turn was correlated with the amount of leaves/sheath in the plants during grinding. The reason behind this lack of strength when dust particles are present lies in the nature and shape of these dust fragments. Although some particles collected in the bottom sieve retained a "fibrous" structure, it consisted mostly of irregular fragments with very low aspect ratio. The 
different composition of stems (highly lignified) and leaves (rich in hemicellulose), and thus the different mechanical strength (hemicellulose-rich particle being weaker) also accounts for the different behavior of what within the text we referred to as "dust" particles (mostly leaf/sheath fragments).

\subsubsection{Influence of the fragment size as a function of genotype}

Given the differences noticed in the reinforcing capacity of the fragments of different sizes, the sizes of the fragments isolated from each genotype were characterized (Table 2 ). The measurements showed some differences in the length, diameter and aspect ratio of the fragments obtained from each genotype. However, such differences were nonstatistically significant. The sieving protocol used selected fragments with a rather homogenous size. For all the genotypes tested, clear improvements on the mechanical properties of composites were detected. As seen previously, the tensile strength of composites reinforced with the sieved miscanthus fragments varied from 33 to $38 \mathrm{MPa}$ compared to 29-33MPa of materials with un-sieved fragments.

Correlation between the tensile strength of composites and the initial size (length and diameter) of the reinforcing fragments was poor $\left(\mathrm{R}^{2}<0.3\right)$, suggesting that the differences observed in the reinforcing capacity of the fragments were not related to the initial sizes of stem fragment but to their composition and/or inherent strength.

Furthermore, even though it is well accepted that the reinforcing capacity of fibers is related to their aspect ratio, no correlation $\left(\mathrm{R}^{2}<0.1\right)$ could be stablished with neither the nominal nor the weighted aspect ratio averages. This result suggests that small changes in the initial size of the fragments had no influence in the properties of composites. In consequence, any change in the strength of the composites has to be caused by another reason. Obviously, fiber attrition during compounding means that the size of the fragments after processing is different (smaller) than their initial size. However, these aspects are genotype dependent, with the different intrinsic mechanical and thermal resistances of fragments leading to different size reduction during processing. Currently under study, these aspects will be reported later.

\subsection{Validation at a different fragment size}

In order to further validate the protocol, composites were prepared from five genotypes with fragments collected in the $200 \mu \mathrm{m}$ sieve and their mechanical properties compared with those of composites reinforced with fragments collected in the $100 \mu \mathrm{m}$ sieve. As expected from results presented in section 3.2, the mechanical performance of the composites reinforced with fragments collected in the sieve with larger pore openings were lower (Figure 5). An important result is that the relative performances of the five tested genotypes followed the same order, suggesting that variations were indeed caused by the different reinforcing capacities of the each genotype and again showing the reliability of the protocol.

\subsection{Validation with different polymeric matrix}

A final validation consisted in the evaluation of the effect of the polymer matrix onto the relative performance of genotypes. To do so, the mechanical performances of composites based on two different polypropylene matrices reinforced with four randomly selected genotypes were compared (Figure 6). Due to the different inherent mechanical properties of the two matrices, clear differences can be observed between the two sets of results. Differences in tensile strength of composites reinforced with the different genotypes were smaller when using the injection grade matrix (PPH5060). Nevertheless, the relative mechanical performance of genotypes remained consistent, 
showing that differences detected in the mechanical properties of composites prepared under the same processing conditions were indeed caused by the genotype characteristics. The protocol which has been developed has the power to discriminate the reinforcement potential of stem fragments coming from different genotypes of miscanthus.

\section{Conclusions}

The use of a large panel of genotypes offered the possibility to assess if it is possible to devise an experimental protocol able to differentiate these genotypes when preparing polymer composites. As shown, when carefully selecting all steps from the preparation of the stem fragments to the mechanical testing, it was possible to clearly and safely classify genotypes in their ability to reinforce a polypropylene matrix. As will be seen in subsequent papers, it is possible to develop such protocols for other plants, and in all cases, very strong correlations were found between the mechanical properties of composites and the biochemical compositions and histological structures of the different genotypes. Miscanthus proved to be interesting materials for composite uses. Composites including PP-g-MA in their formulation show that stem fragments of miscanthus can effectively reinforce the PP matrix in spite of having an aspect ratio below six. Miscanthus stem fragments do not require any chemical modification to behave as reinforcement. A simple milling process was enough to provide fragments with the surface area required to attain a good interphase. Stem fragment size is an important parameter for controlling the tensile strength of composites, with best results being obtained with fragments averaging $600 \mu \mathrm{m}$ in length. Considering the environmental benefit of miscanthus cultivation compared to other plants like flax or hemp [37] and the fact that no pre-treatment is necessary to prepare composites, the use of miscanthus stem fragments is a very attractive solution. This optimized preparation procedure will be used in forthcoming publications for a deeper comparison of miscanthus genotypes correlating mechanical properties with biochemical composition, structure and other parameters like soil quality and weather conditions during growth.

\section{Acknowledgement}

This work was supported by the program Investments for the Future (grant ANR-11BTBR-0006-BFF) managed by the French National Research Agency. The authors want to acknowledge Eastman, Clariant and Chemtura for kindly providing samples of the MA-g-PP's used in this work.

\section{References}

[1] M. Etcheverry, S.E. Barbosa, Glass Fiber Reinforced Polypropylene Mechanical Properties Enhancement by Adhesion Improvement, Materials (Basel). 2012; 5(12) : 1084.

[2] A. Bernasconi, P. Davoli, D. Rossin, C. Armanni, Effect of reprocessing on the fatigue strength of a fibreglass reinforced polyamide, Compos Part A Appl Sci Manuf 2007; 38(3): 710. 
[3] P.-A. Eriksson, A.-C. Albertsson, P. Boydell, K. Eriksson, J.-A.E. Manson, Reprocessing of fiberglass reinforced polyamide 66: Influence on short term properties, Polym Compos 1996; 17(6): 823.

[4] T. Corbière-Nicollier, B. Gfeller Laban, L. Lundquist, Y. Leterrier, J.-A.E. Månson, O. Jolliet, Life cycle assessment of biofibres replacing glass fibres as reinforcement in plastics, Resour Conserv Recycl 2001; 33(4):267.

[5] S.V. Joshi, L.T. Drzal, A.K. Mohanty, S. Arora, Are natural fiber composites environmentally superior to glass fiber reinforced composites?, Compos Part A Appl Sci Manuf 2004; 35(3): 371.

[6] U. Riedel, Biocomposites: Long natural fiber-reinforced biopolymers, in: Polym. Sci. A Compr. Ref. Vol. 10 Polym. a Sustain. Environ. Green Energy, Elsevier, 2012: pp. 295-315.

[7] Y.S. Song, J.R. Youn, T.G. Gutowski, Life cycle energy analysis of fiberreinforced composites, Compos Part A Appl Sci Manuf 2009; 40(8): 1257.

[8] G. Koronis, A. Silva, M. Fontul, Green composites: A review of adequate materials for automotive applications, Compos Part B Eng 2013; 44(1):120.

[9] A. Ashori, Wood - plastic composites as promising green-composites for automotive industries!, Bioresour Technol 2008; 99: 4661.

[10] J. Markarian, Outdoor living space drives growth in wood-plastic composites, Plast Addit Compd 2008; 10(4):20.

[11] P.A. Fowler, J.M. Hughes, R.M. Elias, Biocomposites: technology, environmental credentials and market forces, J Sci Food Agric 2006; 86(12):1781.

[12] O. Faruk, A.K. Bledzki, H.-P. Fink, M. Sain, Biocomposites Reinforced with Natural Fibers: 2000-2010, Prog Polym Sci 2012; 37(11):1552.

[13] J. Summerscales, N. Dissanayake, A. Virk, W. Hall, A review of bast fibres and their composites. Part 2 - Composites, Compos Part A Appl Sci Manuf 2010; 41(10):1336.

[14] H. Ku, H. Wang, N. Pattarachaiyakoop, M. Trada, A review on the tensile properties of natural fiber reinforced polymer composites, Compos Part B Eng 2011; 42(4): 856.

[15] R.M.F. da Costa, S.J. Lee, G.G. Allison, S.P. Hazen, A. Winters, M. Bosch, Genotype, development and tissue-derived variation of cell-wall properties in the lignocellulosic energy crop Miscanthus., Ann Bot 2014; 114(6):1265. 
[16] K. Charlet, C. Baley, C. Morvan, J.P. Jernot, M. Gomina, J. Bréard, Characteristics of Hermès flax fibres as a function of their location in the stem and properties of the derived unidirectional composites, Compos Part A Appl Sci Manuf 2007; 38(8):1912.

[17] E.M. Hodgson, S.J. Lister, A. V. Bridgwater, J. Clifton-Brown, I.S. Donnison, Genotypic and environmentally derived variation in the cell wall composition of Miscanthus in relation to its use as a biomass feedstock, Biomass Bioenerg 2010; 34(5): 652 .

[18] K. Kaack, K.-U. Schwarz, Morphological and mechanical properties of Miscanthus in relation to harvesting, lodging, and growth conditions, Ind Crops Prod 2001; 14(2): 145.

[19] T. Le Ngoc Huyen, C. Rémond, R.M.M. Dheilly, B. Chabbert, Effect of harvesting date on the composition and saccharification of Miscanthus $\mathrm{X}$ giganteus, Bioresour Technol 2010; 101(21): 8224.

[20] S. Belkhir, A. Koubaa, A. Khadhri, M. Ksontini, H. Nadji, S. Smiti, T. Stevanovic, Seasonal effect on the chemical composition of the leaves of Stipa tenacissima L. and implications for pulp properties, Ind Crops Prod 2013; 44 : 56.

[21] K.M.M. Rao, K.M. Rao, Extraction and tensile properties of natural fibers: Vakka, date and bamboo, Compos Struct 2007; 77(3) : 288.

[22] D. Liu, J. Song, D.P. Anderson, P.R. Chang, Y. Hua, Bamboo fiber and its reinforced composites: structure and properties, Cellulose 2012; 19(5):1449.

[23] S. Hanana, A. Elloumi, V. Placet, H. Tounsi, H. Belghith, C. Bradai, An efficient enzymatic-based process for the extraction of high-mechanical properties alfa fibres, Ind Crops Prod 2015; $70: 190$.

[24] J. Summerscales, N.P.J. Dissanayake, A.S. Virk, W. Hall, A review of bast fibres and their composites. Part 1 - Fibres as reinforcements, Compos Part A Appl Sci Manuf $2010 ; 41(10): 1329$.

[25] F.P. La Mantia, M. Morreale, Green composites: A brief review, Compos Part A Appl Sci Manuf 2001; 42(6): 579.

[26] M.C. McCrary-Dennis, O.I. Okoli, A review of multiscale composite manufacturing and challenges, J Reinf Plast Compos 2012; 31(24):1687.

[27] A.M.M. El-Sabbagh, L. Steuernagel, D. Meiners, G. Ziegmann, Effect of extruder elements on fiber dimensions and mechanical properties of bast natural fiber polypropylene composites, J Appl Polym Sci 2014; 131(12):40435. 
[28] G. Gamon, P. Evon, L. Rigal, Twin-screw extrusion impact on natural fibre morphology and material properties in poly(lactic acid) based biocomposites, Ind Crops Prod 2013; 46: 173.

[29] H.D. Rozman, A. Sobra Mulisa, G.S. Tay, A comparison study of lignocellulosic-thermoplastic composites prepared from different compounding techniques, J Appl Polym Sci 2012; 124(6): 4547.

[30] A. Lefeuvre, A. Bourmaud, C. Morvan, C. Baley, Elementary flax fibre tensile properties: Correlation between stress-strain behaviour and fibre composition, Ind Crops Prod 2014; 52 :762.

[31] V. Placet, F. Trivaudey, O. Cisse, V. Gucheret-Retel, M.L. Boubakar, Diameter dependence of the apparent tensile modulus of hemp fibres: A morphological, structural or ultrastructural effect? Compos Part A Appl Sci Manuf 2012; 43(2):275.

[32] K. Oksman, A.P. Mathew, R. Långström, B. Nyström, K. Joseph, The influence of fibre microstructure on fibre breakage and mechanical properties of natural fibre reinforced polypropylene, Compos Sci Technol 2009; 69(11-12):1847.

[33] R. Ramli, R.M. Yunus, M.D.H. Beg, Effects of fiber loading, fiber type, its mesh sizes, and coupling agent on the properties of oil palm biomass/polypropylene composites, J Compos Mater 2011; 45(21):2165.

[34] C.V. Beale, S.P. Long, Seasonal dynamics of the nutrient accumulation and partitioning in the perennial C4 grasses Miscanthus x Giganteus and Spartina Cynosurodies, Biomass Bioenerg 1997; 12(6):419.

[35] L. Strullu, S. Cadoux, M. Preudhomme, M.H. Jeuffroy, N. Beaudoin, Biomass production and nitrogen accumulation and remobilisation by Miscanthus giganteus as influenced by nitrogen stocks in belowground organs, F Crop Res 2011; 121(3):381.

[36] H.W. Zub, M. Brancourt-Hulmel, Agronomic and physiological performances of different species of Miscanthus, a major energy crop. A review, Agron Sustain Dev 2010; 30(2):201.

[37] J. Harvey, A versatile solution? Growing Miscanthus for bioenergy, RenewableEnergyWorld.com. 2007; 10(1). 


\section{Figure captions}

Figure 1: Fiber length distribution of sieved miscanthus fragments as a function of the mesh size of the sieved were they were retained

Figure 2: Mechanical properties of polypropylene reinforced with $30 \%$ miscanthus fragments collected in different sieves. Square symbols: composites with no coupling agent; triangular symbols: coupled composites including 1.5\% MA-g-PP in their formulation.

Figure 3: Tensile strength vs. Young's modulus of composites reinforced with sieved fragments from thirteen different miscanthus genotypes.

Figure 4: Mechanical properties of composites reinforced with fragments of six different miscanthus genotypes $(\diamond=\mathrm{SAC} ; \square=\mathrm{MAL} ;+=\mathrm{H} 5 ; \mathrm{x}=\mathrm{GOL} ; \mathrm{O}=\mathrm{FLO}$; $\triangle=$ GIGB). Full symbols represent the $\%$ of fragments that went through the $200 \mu \mathrm{m}$ sieve and were collected in sieve with $100 \mu \mathrm{m}$ mesh size, whereas open symbols indicates the amount of dust particles that passed through the $100 \mu \mathrm{m}$ sieve.

Figure 5: Tensile strength of composites reinforced with 30\%wt of fragments from five different miscanthus genotypes depending on the sieve where fragments were collected (100 and $200 \mu \mathrm{m}$ mesh size)

Figure 6: Ultimate tensile strength for composites reinforced with 30\%wt of fragments from four different miscanthus genotypes prepared in two different PP matrices. 
Table 1: Mechanical properties of PP-Addilene and composites reinforced with $30 \%$ w/w content of miscanthus fragments obtained from different genotypes.

\begin{tabular}{ccccc}
\hline \hline Genotype & $\begin{array}{c}\text { Weight test bar } \\
(\mathbf{g})\end{array}$ & $\begin{array}{c}\text { Tensile strength } \\
(\mathbf{M P a})\end{array}$ & $\begin{array}{c}\text { Young's Modulus } \\
(\mathbf{G P a})\end{array}$ & $\begin{array}{c}\text { Elongation at } \\
\text { yield }(\boldsymbol{\%})\end{array}$ \\
\hline PP-addilene & $0.902(0.001)$ & $24.0(0.4)$ & $1.15(0.01)$ & $6.40(0.18)$ \\
\hline GRZ & $1.013(0.004)$ & $33.3(0.4)$ & $2.77(0.02)$ & $2.43(0.03)$ \\
YAK & $1.014(0.002)$ & $33.7(0.6)$ & $2.77(0.04)$ & $2.39(0.04)$ \\
FLA & $1.014(0.001)$ & $35.1(0.3)$ & $2.92(0.03)$ & $2.39(0.04)$ \\
FER & $1.015(0.003)$ & $33.4(0.6)$ & $2.78(0.03)$ & $2.40(0.04)$ \\
ROT & $1.016(0.002)$ & $35.2(0.3)$ & $3.07(0.06)$ & $2.32(0.05)$ \\
SIL & $1.013(0.003)$ & $36.4(0.3)$ & $3.09(0.04)$ & $2.24(0.05)$ \\
PUR & $1.014(0.003)$ & $32.5(0.4)$ & $2.77(0.04)$ & $2.26(0.03)$ \\
SAC & $1.014(0.002)$ & $33.4(0.4)$ & $2.81(0.03)$ & $2.38(0.04)$ \\
MAL & $1.015(0.001)$ & $34.2(0.7)$ & $2.83(0.05)$ & $2.35(0.07)$ \\
GOL & $1.016(0.003)$ & $35.4(0.4)$ & $2.97(0.03)$ & $2.29(0.04)$ \\
GIGB & $1.016(0.002)$ & $36.4(0.4)$ & $3.08(0.03)$ & $2.47(0.02)$ \\
FLO & $1.014(0.002)$ & $36.8(0.2)$ & $3.06(0.02)$ & $2.54(0.03)$ \\
H10=H5 & $1.015(0.002)$ & $38.2(0.3)$ & $3.25(0.02)$ & $2.39(0.06)$ \\
\hline \hline
\end{tabular}


Table 2: Length-weighted average fragment length: $\boldsymbol{L}_{w}=\frac{\sum \boldsymbol{L}_{i}{ }^{2}}{\sum \boldsymbol{L}_{\boldsymbol{i}}}$; Diameter-weighted average fragment diameter: $\boldsymbol{D}_{w}=\frac{\sum \boldsymbol{D} \boldsymbol{L}_{i}{ }^{2}}{\sum \boldsymbol{D}_{\boldsymbol{i}}}$;Weighted average aspect ratio: $\frac{\sum\left(\boldsymbol{L}_{\boldsymbol{i}} / \boldsymbol{D}_{i}\right)^{2}}{\sum\left(\boldsymbol{L}_{i} / \boldsymbol{D}_{i}\right)}$; The symbol (+) and (-) preceding the value of $\mathrm{R}^{2}$ indicates positive and negative slope of an hypothetical linear correlation. Values in brackets represent the standard deviation.

\begin{tabular}{|c|c|c|c|c|c|c|c|}
\hline \multirow[b]{2}{*}{ Genotype } & \multirow{2}{*}{$\begin{array}{l}\text { Number of } \\
\text { fragments } \\
\text { measured }\end{array}$} & \multicolumn{2}{|c|}{ Fragment length $(\mu \mathrm{m})$} & \multicolumn{2}{|c|}{ Fragment diameter $(\mu \mathrm{m})$} & \multicolumn{2}{|c|}{ Aspect ratio (L/D) } \\
\hline & & $\begin{array}{c}\text { Nominal } \\
\text { average } \\
(\mathrm{L}) \\
\end{array}$ & $\begin{array}{c}\text { Weighted } \\
\text { average }\end{array}$ & $\begin{array}{c}\text { Nominal } \\
\text { Average } \\
\text { (D) } \\
\end{array}$ & $\begin{array}{l}\text { Weighted } \\
\text { average }\end{array}$ & $\begin{array}{c}\text { Nominal } \\
\text { average }\end{array}$ & $\begin{array}{c}\text { Weighted } \\
\text { average }\end{array}$ \\
\hline FLA & 336 & $397(265)$ & 572 & $86(45)$ & 110 & $6.9(9)$ & 19.0 \\
\hline FLO & 128 & $526(277)$ & 665 & $95(43)$ & 114 & $6.8(5)$ & 10.5 \\
\hline GIGB & 154 & $635(341)$ & 811 & $72(46)$ & 101 & $13(11)$ & 22.7 \\
\hline GOL & 134 & $592(278)$ & 715 & $91(52)$ & 120 & $10.0(11)$ & 21.0 \\
\hline GRZ & 315 & 459 (277) & 623 & $101(46)$ & 121 & $6.2(7)$ & 13.3 \\
\hline H5 & 239 & $518(240)$ & 625 & $89(39)$ & 106 & $7.3(6)$ & 11.9 \\
\hline MAL & 241 & $505(259)$ & 635 & $95(44)$ & 116 & $7.3(8)$ & 15.0 \\
\hline SIL & 156 & $511(302)$ & 684 & $99(43)$ & 117 & $6.5(7)$ & 13.2 \\
\hline \multicolumn{2}{|c|}{$\begin{array}{c}\begin{array}{c}\text { Correlation with tensile } \\
\text { strength of composites } \\
\left(\mathbf{R}^{2}\right)\end{array} \\
\end{array}$} & $(+) 0.25$ & $(+) 0.11$ & $(-) 0.22$ & $(-) 0.21$ & $(+) 0.08$ & $(+) 0.01$ \\
\hline
\end{tabular}


Figure 1

Fiber length distribution as a function of sieve opening

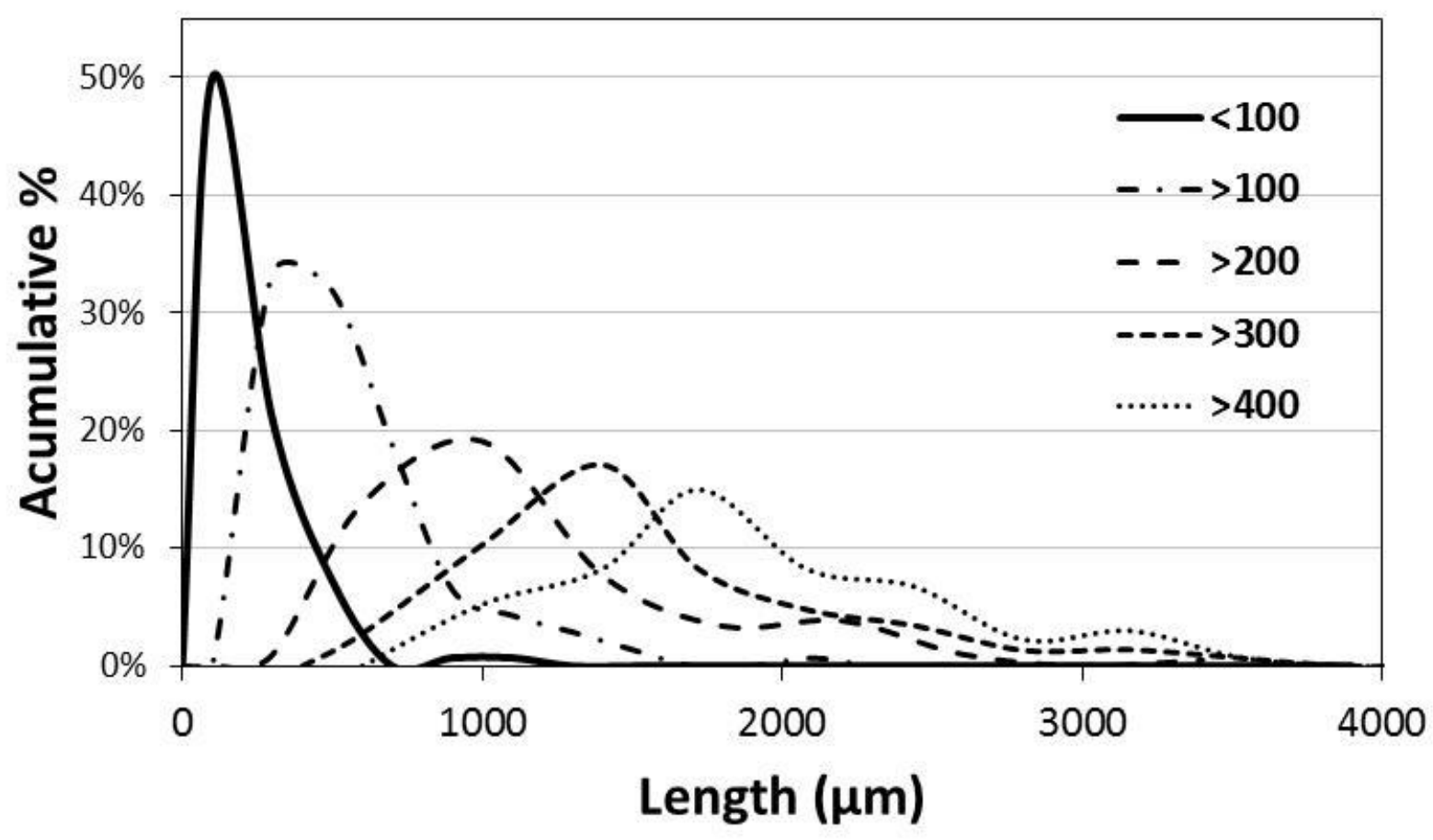

Figure 1: Fiber length distribution of sieved miscanthus fragments as a function of the mesh size of the sieved were they were retained 
Figure 2

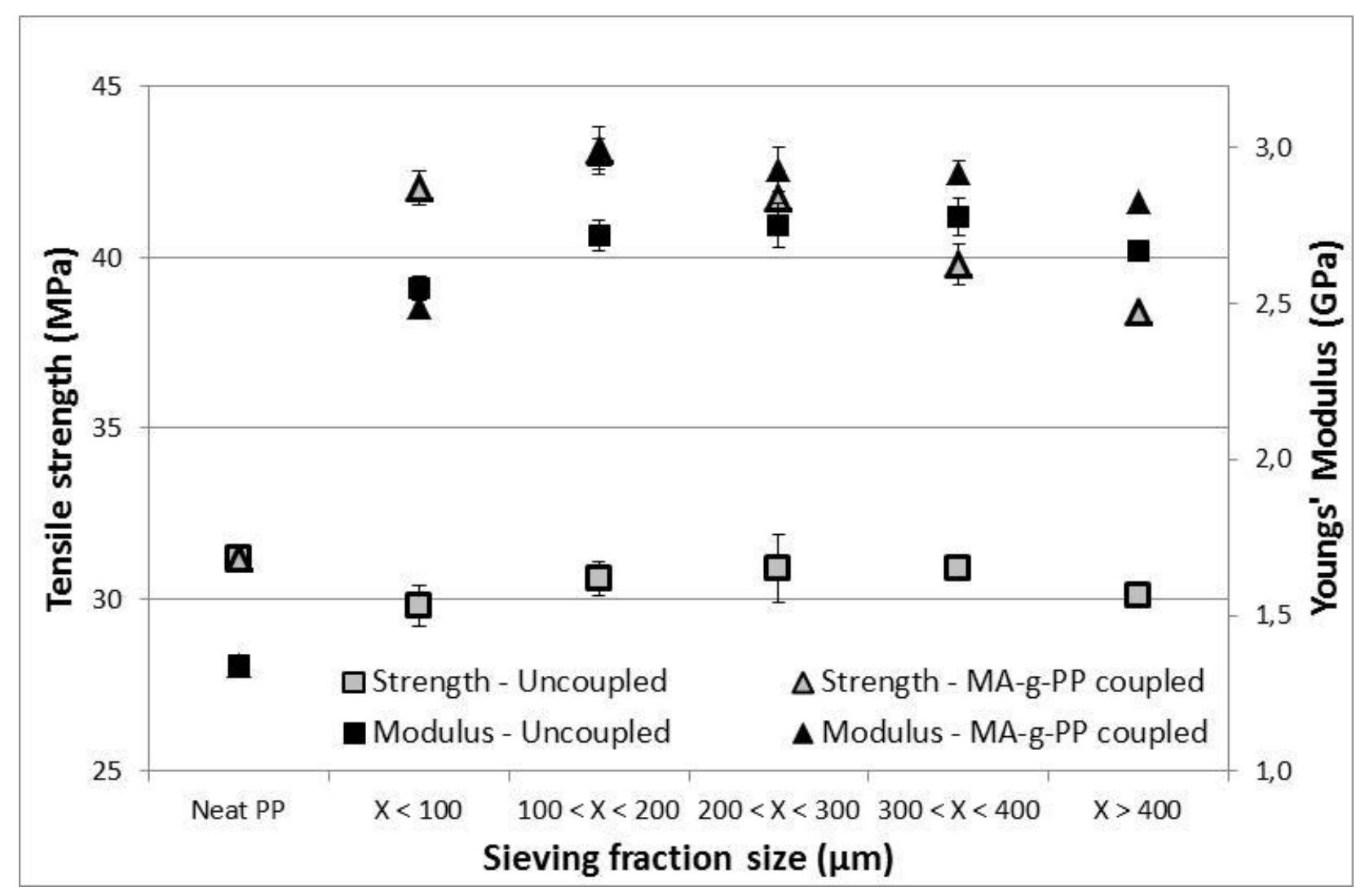

Figure 2: Mechanical properties of polypropylene reinforced with $30 \%$ miscanthus fragments collected in different sieves. Square symbols: composites with no coupling agent; triangular symbols: coupled composites including $1.5 \% \mathrm{MA}-\mathrm{g}-\mathrm{PP}$ in their formulation. 
Figure 3

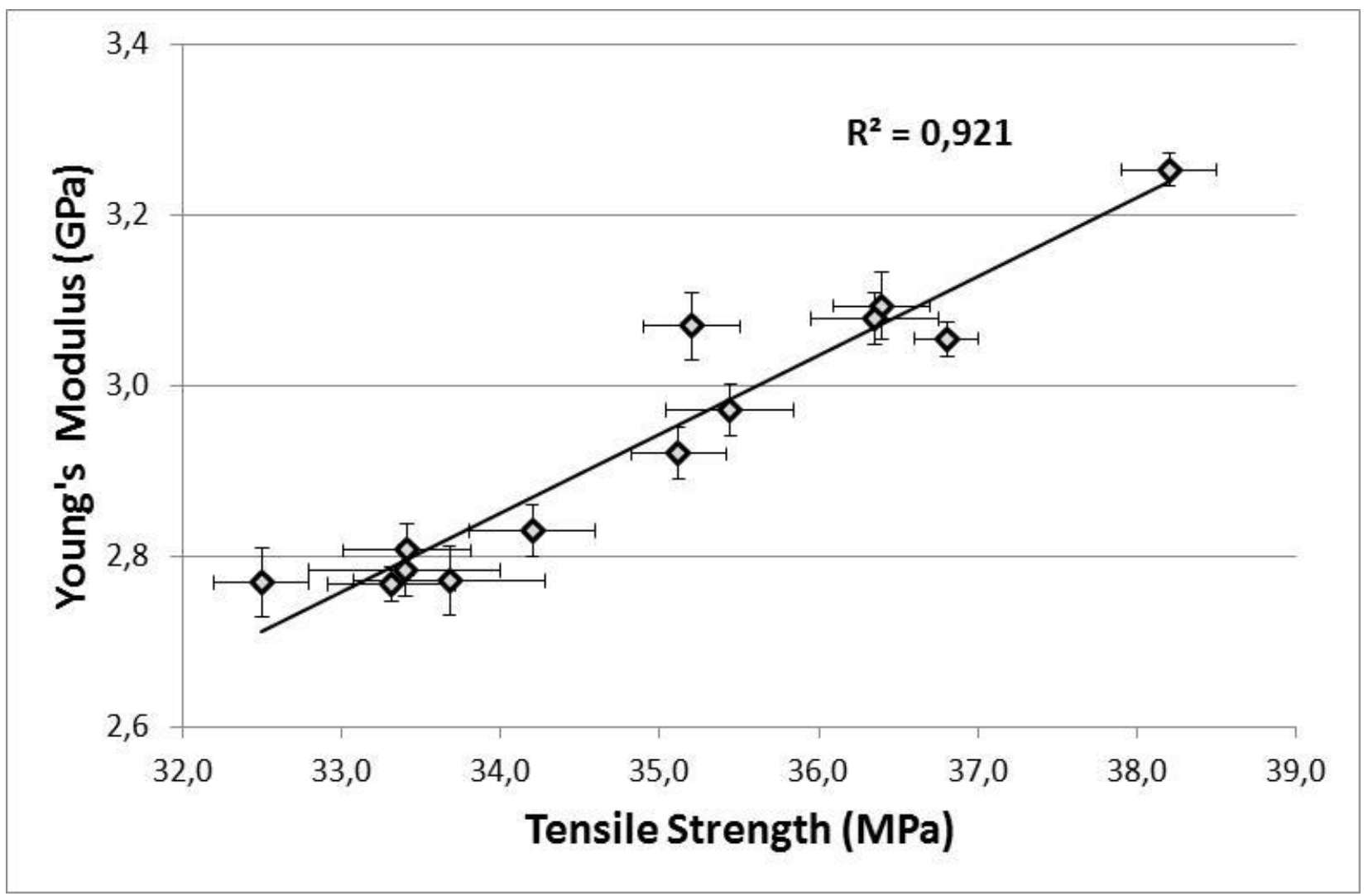

Figure 3: Tensile strength vs. Young's modulus of composites reinforced with sieved fragments from thirteen different miscanthus genotypes. 
Figure 4

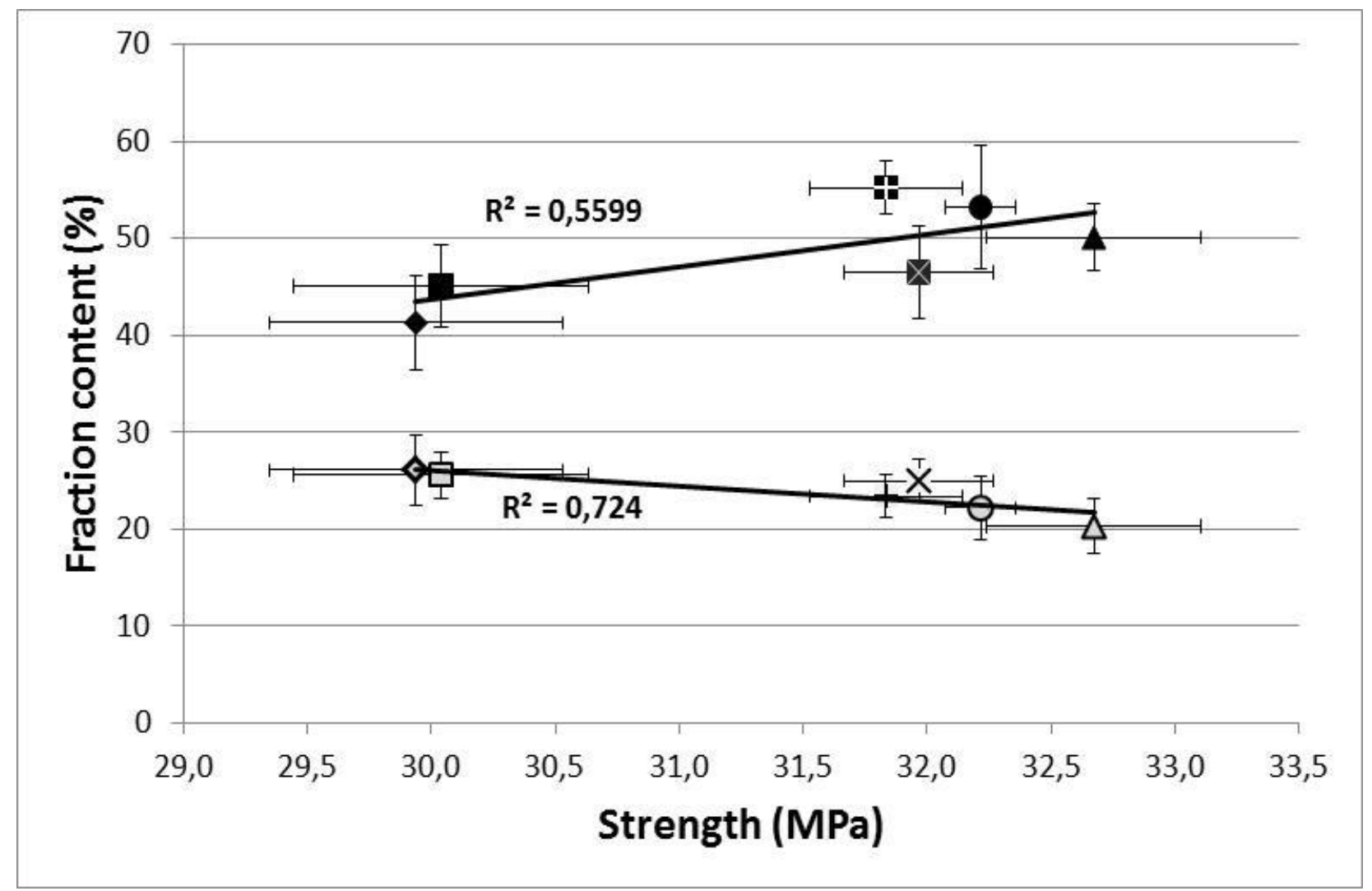

Figure 4: Mechanical properties of composites reinforced with fragments of six different miscanthus genotypes $(\diamond=\mathrm{SAC} ; \square=\mathrm{MAL} ;+=\mathrm{H} 5 ; \mathrm{x}=\mathrm{GOL} ; \mathrm{O}=\mathrm{FLO}$; $\triangle=$ GIGB). Full symbols represent the $\%$ of fragments that went through the $200 \mu \mathrm{m}$ sieve and were collected in sieve with $100 \mu \mathrm{m}$ mesh size, whereas open symbols indicates the amount of dust particles that passed through the $100 \mu \mathrm{m}$ sieve. 
Figure 5

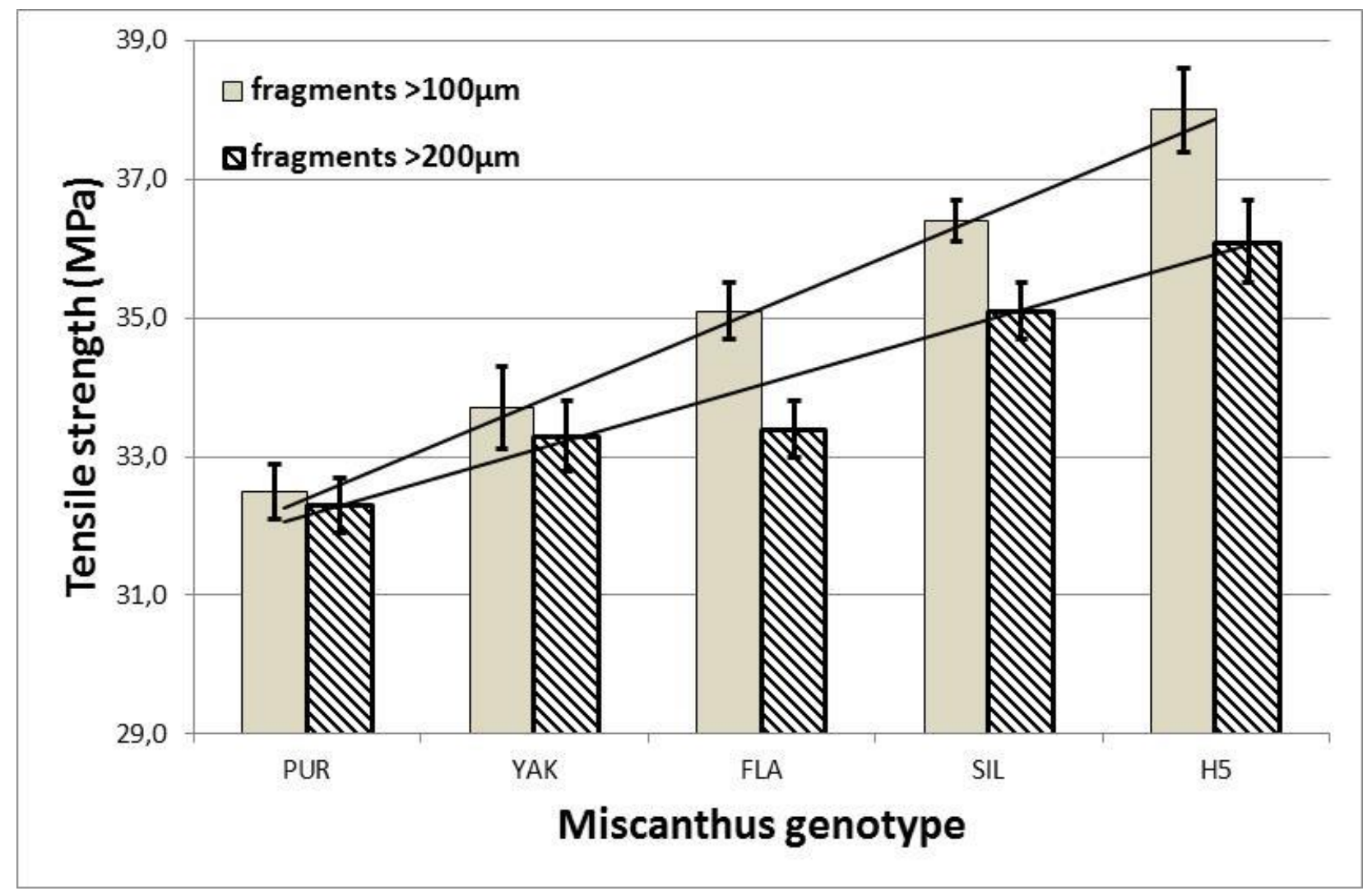

Figure 5: Tensile strength of composites reinforced with 30\%wt of fragments from five different miscanthus genotypes depending on the sieve where fragments were collected

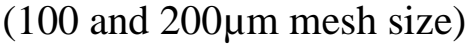


Figure 6

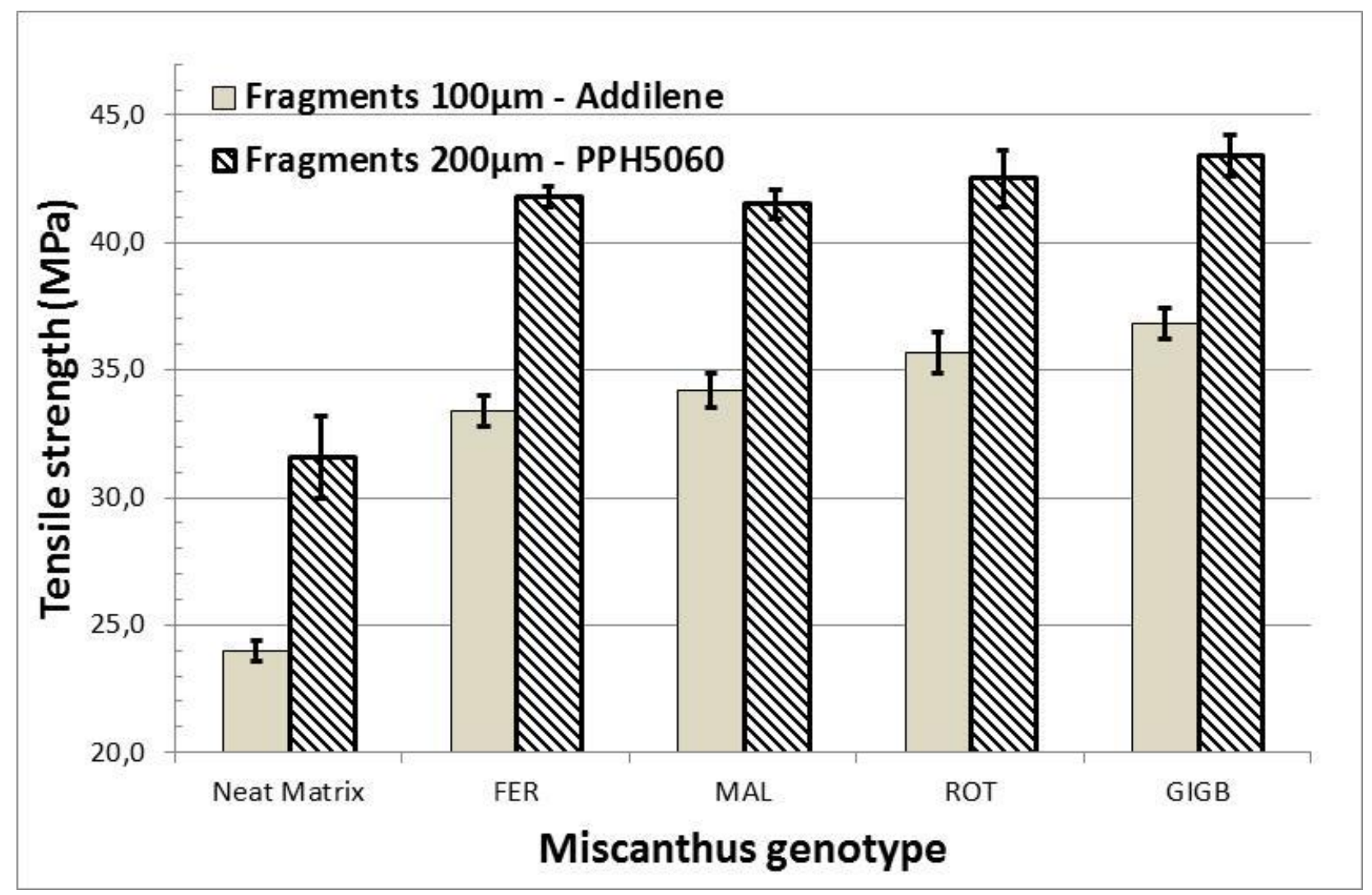

Figure 6: Ultimate tensile strength for composites reinforced with $30 \%$ wt of fragments from four different miscanthus genotypes prepared in two different PP matrices. 